\title{
Construction and Evaluation of Pyramidal Hill for Cassava (Manihot Esculenta Crantz) Production in Bataan, Philippines
}

\author{
Jude Dela Cruz Llenarez, Ricson Lorenzo Ines \\ Department of Agricultural Engineering, Bataan Peninsula State University Abucay Campus, Bataan, Philippines
}

Email address:

rhenz554@yahoo.com (R. L. Ines)

\section{To cite this article:}

Jude Dela Cruz Llenarez, Ricson Lorenzo Ines. Construction and Evaluation of Pyramidal Hill for Cassava (Manihot Esculenta Crantz) Production in Bataan, Philippines. International Journal of Applied Agricultural Sciences. Vol. 4, No. 1, 2018, pp. 7-13.

doi: $10.11648 /$ j.ijaas.20180401.12

Received: December 1, 2017; Accepted: December 18, 2017; Published: January 8, 2018

\begin{abstract}
This study was conducted to assess the effects of pyramidal hill in the growth of cassava. However, as observed, the pyramidal hills did not remain pyramidal in shape due to soil compaction. In this study, three parameters were observed to evaluate the results of the study; crop parameters, soil parameters and yield parameters. There were two blocks that contained four treatments with five replications each treatment. Three of the four treatments were in different dimensions of pyramidal hill while one treatment is non-hilled and conventionally hoed which is used by common farmers. Three measurements of hill were used in reference to the base and height; (T1) $40 \mathrm{~cm}$ by $40 \mathrm{~cm}$, (T2) $50 \mathrm{~cm}$ by $50 \mathrm{~cm}$, (T3) $60 \mathrm{~cm}$ by $60 \mathrm{~cm}$ and (T4) 60 $\mathrm{cm}$ by $10 \mathrm{~cm}$ approximately. As a result, the highest averages of plant height recorded were in T3. In the aspect of soil compaction data based on penetrometer's reading, the highest compaction was recorded in T4, while the rest of treatments had not significant differences. Significant differences were also observed in terms of yield parameters. It was recorded that replications in T3 for both blocks had the highest yield. The used of pyramidal in cassava production showed beneficial effects on the growth and yield of crops. Favorable increase in height was observed through measurements and higher weight was attained among tubers.
\end{abstract}

Keywords: Cassava, Soil Compaction, Cassava Tubers, Soil Erosion, Philippines

\section{Introduction}

Cassava is the second most consumed crop in the Philippines [1]. It is the primary substitute of Filipinos to rice. In most areas of Visayas and Mindanao, cassava is even used as staple food. Cassava is also rich in nutrients, especially in carbohydrates, one of the most probable reasons why it perfectly substitutes rice [2] [3].

Cassava is conventionally planted either in disc plowed or manually hoed soil. It grows more potentially in loose and not water logging soil [4] [5]; thus, soil must be properly cultivated. In the aspect of harvesting, a hill is beneficial when it comes to pulling the roots because the soil will not be that compacted by rains and farmers will no longer need to exert more force in pulling the crops. Construction of hills for each experimental crop will even increase the potential of the soil for it will be loosen even better. It will add space also for the roots to grow and expand; hence additional harvest can be expected.

Most farmers engaging in cassava planting are facing the problem of soil compaction [6] [7]. It is the most inevitable soil condition which is mainly caused by many factors like utilization of heavy equipment, degradation of soil organic material and rainfall intensity. Soil compaction creates impermeable layers within the soil [8] that restrict water and nutrient cycles for favorable crop growth and development. This causes reduced crop growth, impeded root expansion, higher water run-off, soil erosion [9], reduced ground water recharge and loss of soil nutrients. With this, a greater energy input on producing cassava is expected due to the enumerated problems brought by soil compaction created in the actual farming method by our farmers. 
The general objective of the study was to evaluate the effects of pyramidal hill design in the growth and yield of cassava. Specifically, it aimed a.) measure the rate of soil compaction through the use of penetrometer, b.) assess different crop and yield parameters, height of plant, length of cassava tubers, weight of cassava tubers, number of cassava tubers, diameter of cassava tubers and number of cassava tubers per plant, and c.) discuss the interaction of furrow and overhead irrigation method into the parameters considered.

The production of cassava commonly start from the land preparation. The depth of planting and the height or cross sectional width was dependent on the capacity of the tractor with implement including the characteristic and relief of land. The study will increase the furrow height and width compared to the common planting system in terms of yield parameters and crop parameters. The study includes the determination of the interaction of furrow method and the overhead irrigation method. The soil compaction also include in the study.

\section{Materials and Methods}

\subsection{Scope, Limitation and Place of the Study}

The study was limited in using pyramidal hill design with three different measures and using the conventional manually hoed soil for cassava production. The rate of soil compaction was recorded using penetrometer. In addition, different parameters were recorded and computed such as length of cassava tubers, diameter of cassava tubers, weight of cassava tubers, height of plant and number of cassava tubers per plant.

The study was conducted from October 2016 to March 2017 at the Bataan Peninsula State University Abucay Campus, Bataan, Philippines.

\subsection{Materials and Equipment}

Cassava stems- used as planting materials

Hoe- used in cultivating the soil for land preparation

Fertilizer- used to promote growth and development on crops

Water- used for irrigating the crops

Penetrometer- used to determine soil hardness and compaction

Rain Gauge- used to measure rainfall depth and intensity

\subsection{Site Selection}

The site used in the study was an open area that was directly exposed to sun light as cassava naturally requires adequate sun light. It is located in the research area in front of New Men's Dormitory, BPSU Abucay Campus, Bataan, Philippines.

The soil type on the site selected was identified to evaluate its interaction on the study. The soil type in the experimental area was Antipolo Clay. The angle of repose of the specific soil type was considered in the dimensioning and designing of pyramidal hill to reduce its erodibility.

\subsection{Experimental Crop}

A total of 40 cuttings of PRC-24 sweet variety of cassava stem with the same maturity were used in the study. This variety is the most commonly planted cultivar in the country for it can easily adapt any environmental condition and can already produce sizable roots as early as six months. They were randomly distributed in four treatments with two blocks.

\subsection{Experimental Treatments and Design}

"b" - base of the hill

" $h$ " - height of the hill

$\mathrm{T} 1-\mathrm{b}=40 \mathrm{~cm}, \mathrm{~h}=40 \mathrm{~cm}$ pyramidal hill, with $45^{\circ}$ angle of repose

$\mathrm{T} 2-\mathrm{b}=50 \mathrm{~cm}, \mathrm{~h}=50 \mathrm{~cm}$ pyramidal hill, with $45^{\circ}$ angle of repose

T3- $b=60 \mathrm{~cm}, \mathrm{~h}=60 \mathrm{~cm}$ pyramidal hill, with $45^{\circ}$ angle of repose

T4- Control, with $\mathrm{b}=60 \mathrm{~cm}$ and $\mathrm{h}=10 \mathrm{~cm}$

The experimental crops were distributed in Randomized Complete Block Design (RCBD) with four treatment and five replications. There were two blocks which underwent two types of irrigation separately. Block 1 underwent furrow irrigation, while Block 2 underwent overhead irrigation. It contained two factors; hill dimension as factor $\mathrm{A}$ and irrigation method as factor B.

\subsection{Experimental Layout}

Layout had $80 \mathrm{~cm}$ spacing between treatments and $2 \mathrm{~m}$ distance between blocks (Figure 1).

\subsection{Crop Management}

The area was cleaned and freed of debris and grasses. A week of rest period took place to enable the left weeds to grow, then final weeding was done. Pyramidal hill was established manually through the use of hoe, shovel, protractor and meter stick. Measurements were checked through a meter stick and protractor. For the Treatment 4, a hoe was used. Treatments were established 80 centimeters apart. 


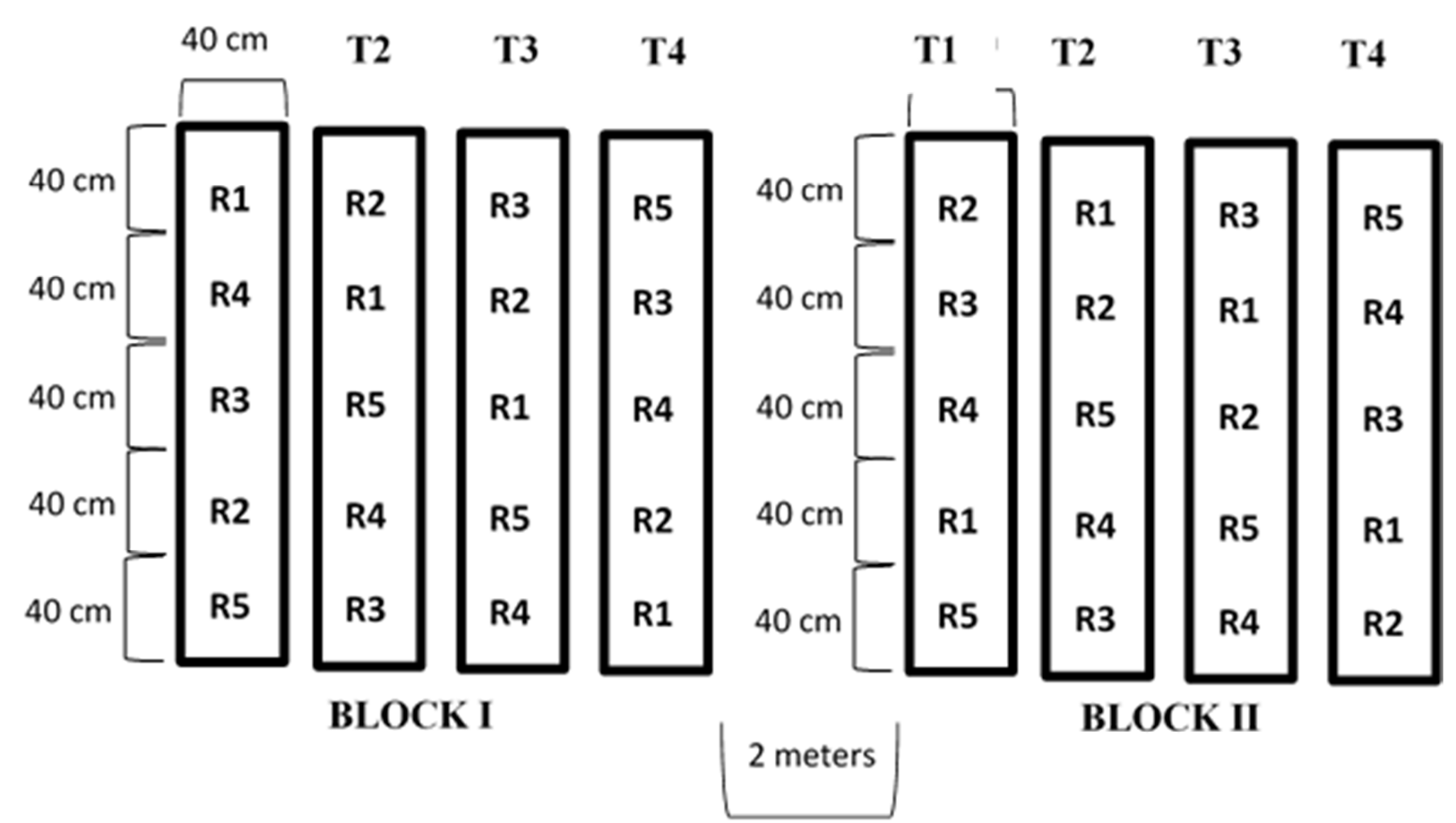

Figure 1. Experimental Layout of the Study.

The hills were constructed manually through the use of hoe, shovel, metering stick, triangle ruler and protractor. The soil was hoed first after weeding and cleaning of the area. Then, before every hill was constructed, a depth of 10 centimeter was established, while its width was according to the base of each hill treatment. Same depth was dug for the treatment 4 which was a non-hilled treatment. This was done in presumption of the fact that the pyramidal hill would soon erode and be deformed.

Once the soil was hilled up, it was formed into pyramidal shape with constant measurement using triangular ruler and protractor in all sides to measure the angle of inclination of each side, the height and the base. The dimension requirement of each hill was accorded to the dimension of hill on the experimental design.

Planting materials were obtained from cassava stalks that are free from pests and diseases. According to Agribusiness Cassava Production Guide, stalks were cut 20-25 centimeter long. The planting materials were derived from the middle part of the stalk. Cuttings were planted slightly inclined of at least 45 degrees where 3-5 centimeters was left uncovered. Missing hills were planted two weeks after crop establishment.

Crops were watered using furrow irrigation method for Block I and overhead irrigation method for Block II during the first 4-5 weeks and during the hottest month of the duration of the study. Physical examination on soil was done to assess if it needed water or not. An average of four pales with 15 liters capacity of water was applied to the whole block when necessary as observed through physical examination considering two different methods of application. Cassava grows extensively in tropical areas, hence, it is resistant to tropical temperature condition like in the Philippines.

According to PCCARRD [10] once established, cassava can grow in areas that receive just $400 \mathrm{~mm}$ of average annual rainfall. But higher yields have been obtained with much higher levels of water supply. Research indicates that maximum root yields are correlated with rainfall totalling about $1,700 \mathrm{~mm}$ during the fourth to eleventh month after planting. Cassava also responds well to irrigation. Root yields increased six fold when the quantity of water supplied by supplementary irrigation [11] matched that of the season's rainfall. According to the rainfall reading of the Bureau of Soil and Water Management, since Bataan receives an average of $641.5 \mathrm{~mm}$ rainfall from October to March, supplementary irrigation should match the total of $1700 \mathrm{~mm}$ for maximum yield.

Although cassava can be grown in poor soils, its performance was adversely affected by such condition and therefore responds highly to fertilization. Deficiencies of major elements do not always result in easily noticeable symptoms, but were reflected in crop yields.

Complete fertilizer, with a total of 250 grams was applied using basal application before planting. Cover the fertilizer with a thin layer of soil. 250 grams of urea was also applied 2 months after planting. It was placed in band 15 centimeters away from the base of the plant. Crops were immediately irrigated to dissolve fertilizer.

Within two months, soil was not tilled anymore, nor disturbed by weeding because the growing roots (fruits) could be hurt. Weeding was done in some parts with evident growth of grass.

There were no evident pest damages and diseases during the study as observed through weekly visual observation.

Plant height is one of the key indicators of the growth of cassava. The growth of the crop is the one that gets much 
disadvantage in the presence of soil compaction, hence, the rate of growth was observed. Growth observation was more efficient since the height was not only measured once, but thrice to observe the speed or rate of growth of the replications in the same period of time. Plant height was measured on the second, fourth and sixth month using a tape meter.

\subsection{Harvesting}

According to Agribusiness Cassava Production Guide 2015 , cassava is ready for harvest from six to seven months after planting. This is sweet if harvested at the right age, but premature, it is tasteless and rots easily. When over mature, it will have harbored mold (bukbok) and/or will be eaten by pests, and the fibers will be tough. In harvesting.

The tuber also indicated the growth of cassava, thus, it was necessary to acquire its measurements. The diameter and length of cassava tubers [12] were measured through a tape meter. They were also weighed to determine the amount of roots (fruit) produced.

\subsection{Penetrometer Reading}

The cone of the penetrometer was inserted in the soil surface. When the guard of the cone reached the soil surface, it was then released from being inserted then the reading will be displayed on its metering cylinder. The exact value in millimeters was then acquired.

\subsection{Data Gathered}

The following data were gathered to analyze the result of the study.

Average Height of Plant (cm). Plant height was measured in centimeters per treatment on the second, fourth and sixth month

Average Length of Cassava Tubers (cm). The total average length of cassava roots in centimeters per treatment will be gathered

Average Weight of Tubers ( $g$ ). The total net weight of cassava tubers in grams per treatment.

Average Number of Cassava Tubers. The total number of tubers per treatment was counted.

Average Diameter of Cassava Tubers (cm). The average diameter of cassava tubers was measured in centimeters per treatment.

Average Height of Plant $(\mathrm{cm})$. Plant height was measured in centimeters per treatment on the second, fourth and sixth month.

Soil Compaction Rate on the Hill ( $\mathrm{mm}$ ). The rate of soil compaction on the hill was recorded using penetrometer.

All the data gathered was subjected to statistical analysis following the Analysis of Variance in factorial design in Randomized Complete Block Design [13]. Factorial Treatment Combination was done to assess the differences among treatment and blocks.

\section{Results and Discussion}

\subsection{Crop Parameters}

Crop parameter considered in this study was plant height. Crops were measured thrice during the study to assess the rate or speed of growth of each plant. The data were used to evaluate if there were significant differences in the growth of cassava in each treatment.

Average Plant Height Six Months after Planting. Table 1 shows the actual height of plant as measured from the field on the sixth month of the study. The highest replication was recorded in B1T3. It was observed that Treatment 1 for both blocks recorded the lowest height. The rest of the treatments for both blocks except from Treatment 1 had not significant differences in terms of height.

Analysis of Variance showed significant effects on the average plant height six months after planting. The recorded measurement from each replication indicated significant differences in plant height using the different treatments of hill dimensions. It indicated higher growth rate due to the fact that crops planted on hilled treatment were able to grow more because of spacious soil surface where its roots expanded well.

Factorial combination showed that Treatment 3 for both blocks recorded the highest plant height. It indicated more favorable growth on Treatment 3 because of adequate space it provided for the roots to penetrate. Block I showed higher increase in height which could be reflected to the irrigation method used in the block due to the fact that irrigation method was the only varying factor between blocks.

Table 1. Actual Height of Plant Six Months after Planting (cm).

\begin{tabular}{|c|c|c|c|c|c|c|c|c|}
\hline \multirow{2}{*}{$\begin{array}{l}\text { IRRIGATION } \\
\text { METHOD }\end{array}$} & \multirow{2}{*}{$\begin{array}{l}\text { HILL } \\
\text { DIMENSION }\end{array}$} & \multicolumn{5}{|c|}{ REPLICATIONS } & \multirow{2}{*}{ TOTAL } & \multirow{2}{*}{ MEAN } \\
\hline & & R1 & $\mathbf{R 2}$ & R3 & R4 & $\mathbf{R 5}$ & & \\
\hline \multirow{4}{*}{ B1 } & $\mathrm{T} 1$ & 190.0 & 196.0 & 203.0 & 189.0 & 177.0 & 955.0 & 191.0 \\
\hline & $\mathrm{T} 2$ & 176.0 & 210.0 & 219.0 & 205.0 & 210.0 & $1,020.0$ & 204.0 \\
\hline & $\mathrm{T} 3$ & 206.0 & 219.0 & 230.0 & 201.0 & 219.0 & $1,075.0$ & 215.0 \\
\hline & $\mathrm{T} 4$ & 217.0 & 223.0 & 212.0 & 199.0 & 201.0 & $1,052.0$ & 210.4 \\
\hline \multirow{3}{*}{ B2 } & $\mathrm{T} 1$ & 193.0 & 189.0 & 198.0 & 198.0 & 195.0 & 973.0 & 194.6 \\
\hline & $\mathrm{T} 2$ & 205.0 & 204.0 & 219.0 & 196.0 & 189.0 & $1,013.0$ & 202.6 \\
\hline & $\mathrm{T} 4$ & 201.0 & 213.0 & 235.0 & 176.0 & 198.0 & $1,023.0$ & 204.6 \\
\hline $\begin{array}{l}\text { Replication Total } \\
\text { Grand Total }\end{array}$ & & 1602.0 & 1663.0 & 1745.0 & 1553.0 & 1585.0 & $8,148.0$ & \\
\hline Grand Mean & & & & & & & & 203.7 \\
\hline
\end{tabular}




\subsection{Soil Parameter}

Soil parameters considered in the study was soil compaction based on penetrometer reading. Such soil parameter was considered due to its significant interaction with the cassava plants.

Average Soil Compaction Reading. Table 2 shows the actual soil compaction as measured in the field using penetrometer. It was recorded that B1T4 had the highest rate of soil compaction with a significant difference among the rest of the treatments. Treatments 1,2 and 3 had no significant differences with each other for both blocks.

Analysis of Variance showed significant effects on soil condition as affected by the irrigation method and hill dimension. The data recorded significant differences among means of treatments. The results indicated that hilling treatment aided in the prevention of too much soil compaction as lower compaction was recorded in hilled treatment. This showed more favorable soil condition that greatly affected the plants.

Factorial treatment combination indicated higher compaction reading in Treatment 4 for both blocks. In addition, Block II recorded higher soil compaction as compared to Block 1. Block II underwent overhead irrigation, while Block I underwent furrow irrigation. Results showed that overhead irrigation increased the compaction on soil surface as analyzed in the data gathered. This is due to the velocity contained as the waters were applied from top of the plant as compared to furrow irrigation wherein waters were applied just on the surface level of the soil.

Table 2. Actual Soil Compaction Reading of Penetrometer (mm).

\begin{tabular}{|c|c|c|c|c|c|c|c|c|}
\hline \multirow{2}{*}{$\begin{array}{l}\text { IRRIGATION } \\
\text { METHOD }\end{array}$} & \multirow{2}{*}{$\begin{array}{l}\text { HILL } \\
\text { DIMENSION }\end{array}$} & \multicolumn{5}{|c|}{ REPLICATIONS } & \multirow{2}{*}{ TOTAL } & \multirow{2}{*}{ MEAN } \\
\hline & & R1 & $\mathbf{R 2}$ & R3 & R4 & R5 & & \\
\hline \multirow{4}{*}{ B1 } & $\mathrm{T} 1$ & 15.3 & 14.3 & 18.3 & 17.0 & 12.3 & 77.2 & 15.4 \\
\hline & $\mathrm{T} 2$ & 12.6 & 14.6 & 16.3 & 12.6 & 9.0 & 65.1 & 13.0 \\
\hline & $\mathrm{T} 3$ & 14.0 & 16.0 & 16.0 & 14.3 & 10.3 & 70.6 & 14.1 \\
\hline & $\mathrm{T} 4$ & 21.6 & 20.6 & 20.3 & 20.0 & 24.3 & 106.8 & 22.6 \\
\hline \multirow{4}{*}{ B2 } & $\mathrm{T} 1$ & 18.3 & 13.3 & 16.3 & 14.0 & 17.6 & 79.5 & 15.9 \\
\hline & $\mathrm{T} 2$ & 14.6 & 12.6 & 17.6 & 21.0 & 13.3 & 79.1 & 15.8 \\
\hline & $\mathrm{T} 3$ & 17.0 & 17.3 & 19.3 & 14.3 & 16.0 & 83.9 & 16.7 \\
\hline & $\mathrm{T} 4$ & 24.0 & 24.0 & 20.6 & 21.6 & 21.0 & 111.2 & 22.2 \\
\hline Replication Total & & 137.0 & 132.7 & 144.7 & 134.8 & 123.8 & \multirow{3}{*}{673.4} & \\
\hline \multicolumn{8}{|l|}{ Grand Total } & \\
\hline Grand Mean & & & & & & & & 34.0 \\
\hline
\end{tabular}

\subsection{Yield Parameters}

Yield parameters considered in the study were diameter, length and weight of cassava tubers. Such components were necessary to assess the overall size of the tubers in relation to soil compaction.

Average Diameter of Cassava Tubers. Table 3 showed the average diameter of cassava tubers as after harvesting. It was recorded that Treatment 3 in Block I had the highest diameter which was 85.20 centimeters. Treatment 1 and Treatment 2 for both blocks recorded lower diameters which indicated lower expansion rate among the treatments as affected by hill dimensions.

Analysis of Variance showed significant differences among treatment means. It indicated significant effects on the diameter of cassava tubers in terms of hill dimension. Results showed that roots among treatments were able to expand desirably. This was because the compaction rate on the normal soil surface and hilled surface had not become intensive enough to significantly affect root expansion.
Factorial treatment combination showed higher average of diameter in Block I in terms of treatments, Treatment 3 obtained highest mean of diameter. This indicated that though not significant effects was analyzed on the diameter of each treatment, Treatment 3 still affected the expansion of cassava tubers in a way that it gained the longest diameter which indicated favorable effects on crop yield. Block I also recorded higher average of diameter as observed in the data. This is in relation to the irrigation method for both blocks. Since overhead irrigation in Block II resulted to increase soil compaction, plants in Block II were not able to expand as fast as the crops in Block I which underwent furrow irrigation.

Average Length of Cassava Tubers. Table 4 shows the average length of cassava tubers as measured after harvesting. It was recorded that Treatment 4 under the Block I had the longest average length. For the Block 2, T3 recorded the longest average length. T1 and T2 recorded shorter length which indicated lower yields among the treatments. 
Table 3. Average Diameter of Cassava Tubers (cm).

\begin{tabular}{|c|c|c|c|c|c|c|c|c|}
\hline \multirow{2}{*}{$\begin{array}{l}\text { IRRIGATION } \\
\text { METHOD }\end{array}$} & \multirow{2}{*}{$\begin{array}{l}\text { HILL } \\
\text { DIMENSION }\end{array}$} & \multicolumn{5}{|c|}{ REPLICATIONS } & \multirow{2}{*}{ TOTAL } & \multirow{2}{*}{ MEAN } \\
\hline & & R1 & $\mathbf{R 2}$ & R3 & R4 & R5 & & \\
\hline \multirow{4}{*}{ B1 } & $\mathrm{T} 1$ & 17.1 & 10.8 & 11.5 & 13.0 & 15.6 & 68.0 & 13.6 \\
\hline & $\mathrm{T} 2$ & 10.4 & 10.8 & 12.3 & 8.2 & 9.7 & 51.4 & 10.2 \\
\hline & $\mathrm{T} 3$ & 18.0 & 17.2 & 17.5 & 14.2 & 18.3 & 85.2 & 17.0 \\
\hline & $\mathrm{T} 4$ & 14.5 & 15.0 & 11.0 & 8.5 & 5.7 & 54.7 & 10.9 \\
\hline \multirow{4}{*}{ B2 } & $\mathrm{T} 1$ & 13.7 & 10.6 & 11.0 & 12.3 & 13.4 & 61.0 & 12.2 \\
\hline & $\mathrm{T} 2$ & 14.0 & 11.0 & 12.5 & 7.05 & 6.0 & 50.5 & 10.1 \\
\hline & $\mathrm{T} 3$ & 19.4 & 10.0 & 21.1 & 13.3 & 11.7 & 75.5 & 15.1 \\
\hline & $\mathrm{T} 4$ & 9.8 & 10.1 & 15.0 & 16.7 & 17.9 & 69.6 & 13.9 \\
\hline Replication Total & & 116.9 & 95.5 & 111.9 & 93.3 & 98.3 & 5160 & \\
\hline Grand Total & & & & & & & 516.0 & \\
\hline Grand Mean & & & & & & & & 12.9 \\
\hline
\end{tabular}

Analysis of Variance showed no significant differences among treatment means. It indicated no significant effects on the length of cassava tubers. Results showed that roots among treatments were able to expand almost on a similar range of length that made their differences not significant. This was because the compaction rate on the normal soil surface and hilled surface had not become intensive enough to significantly affect root expansion.

Factorial treatment combination showed higher average of tuber length in Block I. in terms of treatments, T4 obtained highest mean of length. This indicated that though not significant effects was analyzed on the length of each treatment, Treatment 4 still affected the expansion of cassava tubers in a way that it gained the longest length which indicated favorable effects on crop yield. Block I also recorded higher average of length as observed in the data. This is in relation to the irrigation method for both blocks. Since overhead irrigation in Block II resulted to increase soil compaction, plants in Block II were not able to penetrate as fast as the crops in Block I which underwent furrow irrigation.

Table 4. Average Length of Cassava Tubers (cm).

\begin{tabular}{|c|c|c|c|c|c|c|c|c|}
\hline \multirow{2}{*}{$\begin{array}{l}\text { IRRIGATION } \\
\text { METHOD }\end{array}$} & \multirow{2}{*}{$\begin{array}{l}\text { HILL } \\
\text { DIMENSION }\end{array}$} & \multicolumn{5}{|c|}{ REPLICATIONS } & \multirow{2}{*}{ TOTAL } & \multirow{2}{*}{ MEAN } \\
\hline & & R1 & $\mathbf{R 2}$ & $\mathbf{R 3}$ & R4 & R5 & & \\
\hline \multirow{4}{*}{ B1 } & $\mathrm{T} 1$ & 21.4 & 18.7 & 10.4 & 15.7 & 43.7 & 109.9 & 21.9 \\
\hline & $\mathrm{T} 2$ & 20.4 & 17.3 & 41.9 & 19.3 & 19.0 & 117.9 & 23.5 \\
\hline & $\mathrm{T} 3$ & 25.8 & 22.3 & 21.0 & 42.7 & 30.0 & 141.8 & 28.3 \\
\hline & $\mathrm{T} 4$ & 46.3 & 44.4 & 37.0 & 12.5 & 40.8 & 181.0 & 36.2 \\
\hline \multirow{4}{*}{ B2 } & $\mathrm{T} 1$ & 14.7 & 26.0 & 29.3 & 22.0 & 35.1 & 127.1 & 25.4 \\
\hline & $\mathrm{T} 2$ & 28.0 & 21.3 & 21.0 & 12.7 & 10.3 & 93.3 & 18.6 \\
\hline & $\mathrm{T} 3$ & 23.9 & 22.0 & 46.1 & 24.9 & 25.3 & 142.2 & 28.4 \\
\hline & $\mathrm{T} 4$ & 19.2 & 18.3 & 13.0 & 35.8 & 23.7 & 110.0 & 22.0 \\
\hline $\begin{array}{l}\text { Replication Total } \\
\text { Grand Total }\end{array}$ & & 199.7 & 190.3 & 219.7 & 185.6 & 227.9 & 1023.2 & \\
\hline Grand Mean & & & & & & & & 25.6 \\
\hline
\end{tabular}

Average Weight of Cassava Tubers. Table 5 shows the average weight of cassava tubers which indicated higher weight on Treatment 3 for both blocks. In addition, Treatment 1 and Treatment 2 recorded lower weight which indicated lower expansion rate of roots among the treatments.

Analysis of Variance showed significant effects on the weight of cassava. Significant differences among means were observed as affected significantly by factors, hill dimension and irrigation method. Hill dimension aided in the accumulation of mass of the roots which made it heavier compared to crops planted in hills with smaller dimension. A total harvest of 825.26 kilogram per hectare cassava tubers was the computed yield.

Factorial treatment showed higher weight on Block I. Treatment 3 recorded the highest mean of weight in terms of treatments which was 2,312.8 grams. Block I also recorded higher average weight as observed in the data. This is in relation to the irrigation method for both blocks. Since overhead irrigation in Block II resulted to increase soil compaction, plants in Block II were not able to accumulate mass as fast as the crops in Block I which underwent furrow irrigation. 
Table 5. Average Weight of Cassava Tubers (g).

\begin{tabular}{|c|c|c|c|c|c|c|c|c|}
\hline \multirow{2}{*}{$\begin{array}{l}\text { IRRIGATION } \\
\text { METHOD } \\
\end{array}$} & \multirow{2}{*}{$\begin{array}{l}\text { HILL } \\
\text { DIMENSION }\end{array}$} & \multicolumn{5}{|c|}{ REPLICATIONS } & \multirow{2}{*}{ TOTAL } & \multirow{2}{*}{ MEAN } \\
\hline & & R1 & $\mathbf{R 2}$ & R3 & R4 & R5 & & \\
\hline \multirow{4}{*}{ B1 } & $\mathrm{T} 1$ & 116.0 & 94.7 & 92.7 & 92.5 & 208.6 & 604.5 & 120.9 \\
\hline & $\mathrm{T} 2$ & 125.0 & 123.0 & 138.6 & 105.0 & 136.7 & 628.6 & 125.7 \\
\hline & T3 & 230.0 & 218.0 & 260.0 & 422.2 & 425.7 & $1,555.9$ & 311.1 \\
\hline & $\mathrm{T} 4$ & 238.0 & 330.0 & 153.3 & 110.0 & 80.2 & 911.0 & 182.2 \\
\hline \multirow{3}{*}{ B2 } & $\mathrm{T} 1$ & 33.3 & 112.0 & 95.0 & 53.7 & 128.8 & 422.8 & 84.5 \\
\hline & $\mathrm{T} 2$ & 125.0 & 83.3 & 50.0 & 64.8 & 35.3 & 358.4 & 71.6 \\
\hline & $\mathrm{T} 4$ & 75.6 & 60.3 & 65.0 & 210.0 & 119.5 & 530.4 & 106.0 \\
\hline $\begin{array}{l}\text { Replication Total } \\
\text { Grand Total }\end{array}$ & & 1153.0 & 1080.0 & 1202.4 & 1277 & 1276 & 5987.7 & \\
\hline Grand Mean & & & & & & & & 149.7 \\
\hline
\end{tabular}

Number of Cassava Tubers. Table 6 shows the actual number of cassava tubers as counted during the data gathering. It indicated higher number of tubers in T3 for both blocks. T1 and $\mathrm{T} 2$ for both blocks obtained lower number of tubers.

Analysis of variance showed no significant effect on the number of cassava tubers. There was no significant differences among means as computed in the analysis.

Factorial treatment combination showed higher number of cassava tubers in Block I. Treatment 3 for both blocks recorded higher number of tubers in their respective block.

Table 6. Number of Cassava Tubers.

\begin{tabular}{|c|c|c|c|c|c|c|c|c|}
\hline \multirow{2}{*}{$\begin{array}{l}\text { IRRIGATION } \\
\text { METHOD } \\
\end{array}$} & \multirow{2}{*}{$\begin{array}{l}\text { HILL } \\
\text { DIMENSION }\end{array}$} & \multicolumn{5}{|c|}{ REPLICATIONS } & \multirow{2}{*}{ TOTAL } & \multirow{2}{*}{ MEAN } \\
\hline & & R1 & $\mathbf{R 2}$ & R3 & R4 & R5 & & \\
\hline \multirow{4}{*}{ B1 } & $\mathrm{T} 1$ & 5 & 6 & 6 & 4 & 7 & 28 & 5.6 \\
\hline & $\mathrm{T} 2$ & 4 & 3 & 7 & 4 & 3 & 21 & 4.2 \\
\hline & $\mathrm{T} 3$ & 4 & 5 & 6 & 9 & 4 & 28 & 5.6 \\
\hline & $\mathrm{T} 4$ & 4 & 5 & 3 & 2 & 9 & 23 & 4.6 \\
\hline \multirow{3}{*}{ B2 } & $\mathrm{T} 1$ & 3 & 5 & 4 & 3 & 7 & 22 & 4.4 \\
\hline & $\mathrm{T} 2$ & 4 & 3 & 2 & 1 & 3 & 13 & 2.6 \\
\hline & $\mathrm{T} 4$ & 5 & 6 & 1 & 4 & 6 & 22 & 4.4 \\
\hline $\begin{array}{l}\text { Replication Total } \\
\text { Grand Total }\end{array}$ & & 37 & 39 & 38 & 34 & 45 & 193 & \\
\hline Grand Mean & & & & & & & & 4.83 \\
\hline
\end{tabular}

\section{Conclusion}

Based on the result of the study, the parameters considered obtained relevant values which showed desired effects on the growth and yield of cassava. According to the result of the analysis of the first parameter, the plant height, higher growth rate was observed in the hilled treatments. In addition, the second parameter which was the soil compaction reading of penetrometer also recorded higher compaction rate in $\mathrm{T} 4$ which was a non-hilled treatment; hence, caused lower growth response of its replications. It was also concluded that hill dimensions aided in the accumulation of mass of the tubers as observed in its weight analysis in spite of the not significant differences among the diameter, length and number of tubers.

\section{References}

[1] PCCARRD. Cassava Production Guide. 2013. Manila, Philippines.

[2] Food and Agricultural Organization. 2011. FAO, Rome, Italy.

[3] Food and Agricultural Organization. 1995. Production Yearbook 49. FAO, Rome, Italy.
[4] Agribusiness Cassava Production Guide. 2015. Manila, Philippines.

[5] SEESAHAI, A. and OUSMAN, M. R. Understanding Cassava Plant. 2015. India.

[6] DEJONG-HUGHES et. al. 2015. United States of America.

[7] MCKENZIE, et. al. 2013. United States of America.

[8] DELROY, et. al. 1986. India.

[9] RITTER, JIM P. 2015. Soil Erosion Causes and Effects. California, USA.

[10] PCCARRD Cassava Production. 2002. Manila, Philippines.

[11] HANSEN, V. E., ISRAELSEN, O. W., and STRINGHAM, G. E. (1980). Irrigation Principles and Practices (4 ${ }^{\text {th }}$ ed.). New York, USA.

[12] CALPE, A, 1991. Roots, tubers, and plantains: Recent trends in productions, trade, and use. Pages 11-40 in: Proc. of the F A 0 Expert Consultation. Roots, Tubers, Plantains, and Bananas in Animal Feeding, CIAT, Cali, Colombia.

[13] GOMEZ K. A. and GOMEZ A. A. 1983. Statistical Procedures for Agricultural Research, $2^{\text {nd }}$ edition. A WileyInterscience Publication. pp 383-38. 